ISSN 2333-8385

\title{
Life Satisfaction Of Korean Elderly Parents According To Offspring Gender: A Kangwha Cohort Study
}

Lee $\mathrm{M}^{1}$, Kim $\mathrm{SH}^{2}$, Ohrr $\mathrm{H}^{3}$, Park EC ${ }^{* *}$

Review Article

${ }^{1}$ Department of Health Management and Policy, College of Public Health, University of Iowa, 105 River Street, N265 CPHB, Iowa City, IA 52242, U.S.A.

${ }^{2}$ Graduate School of Public Health, Yonsei University, 134 Shinchon-dong, Seodaemun-gu, Seoul, Korea.

${ }^{3}$ Department of Preventive Medicine, Yonsei University College of Medicine, 134 Shinchon-dong, Seodaemungu, Seoul, Korea.

${ }^{4}$ Department of Preventive Medicine and Public Health, Institute of Health Services Research, Yonsei University College of Medicine, 134 Shinchondong, Seodaemun-gu, Seoul, Korea.

\section{Abstract}

Background: The aging population trend is increasing globally and raises social concerns regarding life satisfaction of elderly people. Offspring are perceived to be a significant factor for Korean elderly people. This study identified whether elderly life satisfaction was related to offspring gender.

Methods: This cross-sectional study consisted of 2,875 respondents (male, 7,176; female, 1,699) aged 65 years or older from the Kangwha Cohort Study. Analysis of variance and linear regression model were used to analyze the association between offspring gender and life satisfaction. The variables related to life satisfaction were controlled for in the present study.

Results: Elderly Korean women who had son(s) and daughter(s) scored on average 6.491 points $(p=0.000)$ higher on the Life Satisfaction Index (LSI) than women with no children. Parents who were 75-84 years old and had only son(s) scored on average 6.166 points (p $=0.034)$ higher on the LSI than parents of the same age with no children after adjusting for age, marital status, occupation, education, chronic disease, smoking, and alcohol consumption.

Conclusion: Life satisfaction of elderly Korean parents varied according to offspring gender. The results may be related to ideology of the nuclear family, tradition of male child preference, importance of social support, and vulnerability of the social security system as Korean social cultural characteristics.

Key Words: Gender; Offspring; Life Satisfaction; Elderly; South Korea.

\section{*Corresponding Author:}

Eun-Cheol Park

Department of Preventive Medicine and Public Health, Institute of Health Services Research, Yonsei University College of Medicine, 134 Shinchon-dong, Seodaemun-gu, Seoul, Korea.

Tel: 82-2-2228-1862; Fax: 82-2-392-8133

E-mail: ecpark@yuhs.ac

Received: October 09, 2013

Accepted: November 22, 2013

Published: November 23, 2013

Citation: Lee M, Kim SH, Ohrr H, Park EC. (2013). Life Satisfaction of Korean Elderly Parents According to Offspring Gender: A Kangwha Cohort Study, Int J Translation Community Dis, 01(01), 01-05. doi: http:/ /dx.doi.org/10.19070/2333-8385-130001

Copyright: Park EC ${ }^{\odot}$ 2013. This is an open-access article distributed under the terms of the Creative Commons Attribution License, which permits unrestricted use, distribution and reproduction in any medium, provided the original author and source are credited.

\section{Introduction}

The aging population trend is increasing globally. The most advanced welfare countries have become aging societies, in which $7 \%$ of the entire population is composed of older people. Koreans aged 65 years and older accounted for $11.3 \%(5,420,000$ people) of the population in 2011. If this trend continues, the aging population rate is expected to be $14.3 \%$ in 2018 and $20.8 \%$ in
2026; thus, the Korean society will be considered an aged society and super-aged society, respectively [1].

This rapid increase in older people causes the elderly to comprise the majority of the population and increases social concern regarding the life satisfaction of the elderly. Life satisfaction, a term used since the 1960s, refers to the responses to individual and external factors (social, economic, and environmental). Measurement methods of life satisfaction vary according to researchers, and different detailed factors are used among the external factors [2].

Numerous studies to date have been conducted regarding factors pertaining to life satisfaction of the elderly. Generally, socio-economic status, subjective health and social support were reported to be important variables in life satisfaction of the elderly; [3-8] in Korea, economic status was especially important [9]. In addition, a gender gap regarding life satisfaction has been observed in the elderly $[10,11]$. Based on studies regarding life satisfaction factors of elderly Koreans, satisfaction related to offspring represented a measurement of successful aging [12].

Reports show that life satisfaction through the success of offspring and life reflected through offspring correlated with elderly life satisfaction $[13,14]$. Consequently, offspring were perceived to be a significant factor in the lives of elderly Koreans.

In this study, we identified whether elderly life satisfaction was related to offspring gender. The relationship between offspring 
gender and elderly life satisfaction was analyzed. The offspring were divided into four groups; no children, only son(s), only daughter(s), and son(s) and daughter(s). The life satisfaction among the four groups was compared in order to identify whether a son preference exists in Korea $[15,16]$ as in most Asian countries [17-22].

\section{Materials and Methods}

\section{Data and Sample}

The primary survey for the Kangwha Cohort was conducted in March 1985 [23-32]. Kangwha County is a rural island in South Korea located $50 \mathrm{~km}$ from Seoul with a mostly agricultural population. The population in 1993 was 71,116, and the number of residents who were $\geq 55$ years of age in February 1985 was 9,378. Among them, 67.9\% (or 6,372 residents) participated in the primary survey. In March 1994, a secondary survey, including interviews for demographic characteristics, Mini-Mental State Examination (MMSE), Activities of Daily Living (ADL), and Instrumental Activities of Daily Living (IADL), as well as Life Satisfaction Index (LSI), was performed. The present study used the data from the 'Kangwha Cohort Study' which was conducted in March 1994. Participants who provided insufficient information were excluded, and the final study population was 2,875 respondents (male, 7,176; female, 1,699) aged 65 years or older. The Institutional Review Board of Human Research of Yonsei University approved the study (Approval No. 4-2007-0182).

\section{Measures}

The investigators interviewed each subject using a structured questionnaire for demographic characteristics, including age, sex, education, chronic disease, marital status, occupation, health behaviors (smoking and drinking), offspring gender, and LSI. Life satisfaction was assessed by the LSI-A index, which was first prepared, validated, and published by Neugarten et al [33, 34]. The internal consistency reliability coefficient (Cronbach's alpha) was computed at 0.82 in a Korean study with 600 elderly subjects. Of the 20 items in the questionnaire, 12 items were positively worded; 0,1 , and 2 points were assigned to "disagree," "don't know" and "agree" answers, respectively. The scores that could be achieved from LSI-A ranged between 0 and 40 points. Offspring were divided into four groups: no children, only son(s), only daughter(s), and son(s) and daughter(s).

\section{Statistical analysis}

Characteristics of the study sample were summarized by descriptive statistics such as mean, standard deviation (SD), and percentage. Analysis of variance and linear regression model were used to analyze the association between offspring gender and life satisfaction. All variables measured in the study were controlled for in our multivariate analysis. The adjusted variables were age, marital status, occupation, education, chronic disease, smoking, and alcohol drinking. A significance level of $\mathrm{p}<0.05$ was used for all tests. Analyses were performed with SAS Windows version 9.1.

\section{Results}

\section{Sample Characteristics}

General characteristics are presented in Table 1. The survey consisted of a total of 2,875 participants. The mean LSI of the study participants was $20.7 \pm 9.6$. The mean age of the study participants was $74.1 \pm 6.3$ years. The mean number of sons of the study participants was $2.5 \pm 1.3$. The mean number of daughters of the study participants was $2.6 \pm 1.4$. Most participants were female $(59.5 \%)$, had no education $(66.0 \%)$, had no chronic disease $(59.1 \%)$, and were non-smokers $(58.5 \%)$ and non-drinkers

Table 1. Baseline characteristics of the study population

\begin{tabular}{|c|c|}
\hline Characteristic & Kangwha Cohort Study $(\mathrm{n}=2,875)$ \\
\hline \multicolumn{2}{|c|}{ Mean \pm SD } \\
\hline Age (years) & $74.1 \pm 6.3$ \\
\hline Life Satisfaction Index & $20.7 \pm 9.6$ \\
\hline \multicolumn{2}{|l|}{ Number of Offspring } \\
\hline Sons & $2.5 \pm 1.3$ \\
\hline Daughters & $2.6 \pm 1.4$ \\
\hline \multicolumn{2}{|c|}{$\mathrm{N}(\%)$} \\
\hline \multicolumn{2}{|l|}{ Chronic disease } \\
\hline Ever & $1,164(40.5)$ \\
\hline Never & $1,711(59.5)$ \\
\hline \multicolumn{2}{|l|}{ Gender } \\
\hline Male & $1,176(40.9)$ \\
\hline Female & $1,699(59.1)$ \\
\hline \multicolumn{2}{|l|}{ Marital status } \\
\hline Yes & $1,630(56.7)$ \\
\hline No & $1,245(43.3)$ \\
\hline \multicolumn{2}{|l|}{ Occupation } \\
\hline Agriculture & $2,394(83.3)$ \\
\hline Non-agriculture & $481(16.7)$ \\
\hline \multicolumn{2}{|l|}{ Education } \\
\hline No & $1,897(66.0)$ \\
\hline
\end{tabular}




\begin{tabular}{|c|c|}
\hline Elementary & $843(29.3)$ \\
\hline High School & $135(4.7)$ \\
\hline \multicolumn{2}{|l|}{ Smoking } \\
\hline Current & $944(32.8)$ \\
\hline Former & $249(8.7)$ \\
\hline Never & $1,682(58.5)$ \\
\hline \multicolumn{2}{|l|}{ Alcohol drinking } \\
\hline Drinker & $823(28.6)$ \\
\hline Former & $160(5.6)$ \\
\hline Non-drinker & 1,892 (65.8) \\
\hline
\end{tabular}

Table 2. Life Satisfaction Index (LSI) according to gender

\begin{tabular}{|c|c|c|c|c|c|c|c|c|c|c|c|c|}
\hline \multirow{2}{*}{ Offspring gender } & \multicolumn{4}{|c|}{ Total(n = 1978) } & \multicolumn{4}{|c|}{ Male $(n=852)$} & \multicolumn{4}{|c|}{ Female $(n=1,126)$} \\
\hline & $\mathrm{n}$ & Mean & SD & $p$ & $\mathrm{n}$ & Mean & SD & $\mathrm{p}$ & $\mathbf{n}$ & Mean & SD & $\mathrm{p}$ \\
\hline No children & 37 & 13.6 & 8.7 & \multirow{4}{*}{$<0.0001 * *$} & 3 & 16 & 5.3 & \multirow{4}{*}{0.3291} & 34 & 13.4 & 9 & \multirow{4}{*}{$<0.0001^{* *}$} \\
\hline Only son(s) & 179 & 20.4 & 9.9 & & 77 & 21.2 & 9.4 & & 102 & 19.8 & 10.3 & \\
\hline Only daughter(s) & 89 & 15.5 & 10 & & 28 & 18.7 & 11.6 & & 61 & 14.1 & 8.8 & \\
\hline Son(s) and daughter(s) & 1673 & 21.2 & 9.4 & & 744 & 21.4 & 8.9 & & 929 & 21.1 & 9.8 & \\
\hline
\end{tabular}

${ }^{*} \mathrm{p}<0.05,{ }^{* *} \mathrm{p}<0.01$

Table 3. Life Satisfaction Index (LSI) according to age group

\begin{tabular}{|c|c|c|c|c|c|c|c|c|c|c|c|c|}
\hline \multirow{2}{*}{ Offspring gender } & \multicolumn{4}{|c|}{$65-74$ years $(n=1,239)$} & \multicolumn{4}{|c|}{$75-84$ years $(n=643)$} & \multicolumn{4}{|c|}{$85+$ years $(n=96)$} \\
\hline & $\mathrm{n}$ & Mean & SD & $\mathrm{p}$ & $\mathrm{n}$ & Mean & SD & $\mathrm{p}$ & $\mathbf{n}$ & Mean & SD & $\mathrm{p}$ \\
\hline No children & 23 & 13.6 & 7.1 & \multirow{4}{*}{$0.0002^{* *}$} & 13 & 13.2 & 11.5 & \multirow{4}{*}{$<0.0001 * *$} & 1 & 19 & 0 & \multirow{4}{*}{0.0642} \\
\hline Only son(s) & 119 & 20.6 & 9.8 & & 54 & 19.9 & 10.2 & & 6 & 22 & 11.7 & \\
\hline Only daughter(s) & 52 & 17.9 & 10.6 & & 29 & 11.7 & 8 & & 8 & 14.1 & 7.8 & \\
\hline Son(s) and daughter(s) & 1045 & 21.2 & 9.5 & & 547 & 21 & 9.3 & & 81 & 23.2 & 8.9 & \\
\hline
\end{tabular}

${ }^{*} \mathrm{p}<0.05,{ }^{* *} \mathrm{p}<0.01$

\section{$(65.8 \%)$.}

\section{Comparison of LSI According to Offspring Gender}

The LSI score for the four different offspring groups (no children, only son(s), only daughter(s), and son(s) and daughter(s)) are displayed in Table 2 (gender groups) and Table 3 (age groups). The son(s) and daughter(s) group had a significantly higher LSI score than the other groups. Women who had only son(s) had a 5.7 point higher LSI score than women who had only daughter(s). In all age groups, the son(s) and daughter(s) group had a higher LSI score than the other groups.

Adjusted Association between Offspring Gender and LSI
The LSI score for the four different offspring groups is displayed in Table 4. In multivariate analysis, the no children group was used as the reference group. Women who had only son(s) scored an average 5.702 points $(p=0.003)$ higher on the LSI than the reference group, after adjusting for age, marital status, occupation, education, chronic disease, smoking, and alcohol drinking. Women who had son(s) and daughter(s) scored an average 6.491 points ( $\mathrm{p}$ $=0.000)$ higher on the LSI than the reference group, after adjusting for the same covariates. No significant interaction effects were found between offspring gender and LSI among men. Parents who were 65-74 years old and had only son(s) scored an average 6.151 points $(p=0.005)$ higher on the LSI than the reference group. Parents who were 65-74 years old and had both son(s) and daughter(s) scored an average 6.511 points $(\mathrm{p}=0.001)$ higher on

Table 4. Life Satisfaction Index (LSI) according to offspring gender

\begin{tabular}{|c|c|c|c|c|c|c|c|c|c|c|c|c|}
\hline \multirow{2}{*}{$\begin{array}{l}\text { Offspring } \\
\text { gender }\end{array}$} & \multicolumn{2}{|c|}{ Total } & \multicolumn{2}{|c|}{ Male } & \multicolumn{2}{|c|}{ Female } & \multicolumn{2}{|c|}{$65-74$ years } & \multicolumn{2}{|c|}{$75-84$ years } & \multicolumn{2}{|c|}{$85+$ years } \\
\hline & LSI & $\mathrm{p}$ & LSI & $\mathrm{p}$ & LSI & $\mathrm{p}$ & LSI & $\mathrm{p}$ & LSI & $\mathrm{p}$ & LSI & $\mathrm{p}$ \\
\hline $\begin{array}{l}\text { No } \\
\text { children }\end{array}$ & reference & & reference & & reference & & reference & & reference & & reference & \\
\hline Only son(s) & 5.917 & 0.001 ** & 2.891 & 0.584 & 5.702 & $0.003^{* *}$ & 6.151 & $0.005^{* *}$ & 6.166 & $0.034 *$ & 3.464 & 0.751 \\
\hline $\begin{array}{l}\text { Only } \\
\text { daughter(s) }\end{array}$ & 1.068 & 0.562 & 0.906 & 0.868 & -0.252 & 0.904 & 3.263 & 0.17 & -1.807 & 0.564 & -6.586 & 0.529 \\
\hline $\begin{array}{l}\text { Son(s) and } \\
\text { daughter(s) }\end{array}$ & 6.373 & $<0.0001^{* *}$ & 3.008 & 0.562 & 6.491 & $0.000 * *$ & 6.511 & $0.001^{* *}$ & 6.609 & $0.013^{*}$ & 3.307 & 0.740 \\
\hline
\end{tabular}

${ }^{*} \mathrm{p}<0.05,{ }^{*} \mathrm{p}<0.01,{ }^{*}$ Adjusted for age, marital status, occupation, education, chronic disease, smoking, and alcohol drinking 
the LSI than the reference group. Parents who were 75-84 years old and had only son(s) scored an average 6.166 points $(p=0.034)$ higher on the LSI than the reference group after adjusting for the same covariates.

\section{Discussion}

In this study, we analyzed elderly life satisfaction according to offspring gender and age in Korea. In general, the son(s) and daughter(s) group was highest in life satisfaction, followed in descending order by the only son(s), only daughter(s), and no children groups. This result reflected the ideology of a nuclear family, tradition of male child preference, importance of social support, and vulnerability of social security system as Korean social cultural characteristics.

\section{Ideology of a Nuclear Family}

First, the life satisfaction of elderly parents with offspring was higher than parents without offspring. This result was related to the regional characteristics of Kanghwa County, which is mainly a farming community. In a traditional agricultural society, children represent an available workforce and are indispensable for family succession. At the time of the investigation in 1993, industrialization was somewhat advanced, and there was a widespread ideology of a nuclear family in South Korea. A nuclear family, by definition, is composed of heterosexual parents and their children, with the father and mother conducting traditional roles (instrumental role and expressive role, respectively) [35]. According to the nuclear family ideology, children of a single-parent family may be abnormal and their life satisfaction could be low.

\section{Male Preference}

The reason why the life satisfaction of the only son(s) group was higher than the only daughter(s) group may be related to male preference and women's low status in Korea. Recently, the male preference has declined among young parents in the Korean society, and thus there is a new saying, "foolish father loving daughter." According to Chung and Gupata (2007), the decline in male preference is due to norm changes and improvement in urbanization and education [36]. However, in 1993, older people in rural areas had the traditional preference for a son because they were the generation who thought highly of the paternal line, and having a son was an important factor in life satisfaction.

If there was (were) son(s), the life satisfaction of the female parent was higher than the male parent. This result could be due to the woman's status in Korean society, which was guaranteed only through birth of a son. Wilson et al. reported that men prefer instrumental support while women prefer emotional support.[37] For female elderly parents, existence of a son implies not only the securing of instrumental support for living costs, but also emotional support for occupying a more stable position in the family. The elderly parents' daughters in their third and fourth decades of life largely lived in urban areas apart from their parents and did not have a formal obligation to support them. Most of the daughters could not afford to provide instrumental support to their parents because they could not engage in economic activities due to childbirth and rearing.

\section{Social Support}

The result that the life satisfaction of the son(s) and daughter(s) group was highest shows that emotional support and instrumental support were important for elderly life satisfaction. Social support is generally classified into two categories, instrumental role and expressive (or emotional) role. While instrumental support refers to the various types of tangible help that others may provide (e.g., money, information), expressive (or emotional) role refers to what people do that make us feel loved and cared for and bolsters our sense of self-worth (e.g., talking over a problem, providing encouragement/positive feedback) [38]. For example, a son has an instrumental role in the provision of a living cost or allowance to his parents, and a daughter has an expressive (or emotional) role in the exchange of personal information with her parents; thus, the life satisfaction of the son(s) and daughter(s) group was highest among the four groups.

\section{Social Security System}

The result that life satisfaction of the only daughter(s) group was the lowest among the four groups and was lower than the no children group appears relevant to the Korean social security system, under which elderly people with offspring cannot receive any social security benefits, even if their daughter has no economic capacity to support them. In other words, the parents in the only daughter(s) group did not receive instrumental support from their offspring as in the other groups with sons and did not get social security benefits because of the existence of female offspring, unlike the no children group.

\section{Conclusion}

The life satisfaction of elderly Korean parents varied according to offspring gender. Life satisfaction of Korean elderly parents was highest in the son(s) and daughter(s) group and lowest in the only daughter(s) group. This result could be explained by the ideology of the nuclear family, tradition of male child preference, importance of social support, and vulnerability of the social security system as Korean social cultural characteristic.

This study has strengths in that offspring presence is an important and influential factor on elderly life satisfaction, and further, elderly life satisfaction varies according to the offspring gender. However, this study has several limitations. First, the Kangwha Cohort data targeted the elderly in a local area; thus, the results cannot be generalized to the entire elderly Korean population. Second, we could not identify causal relationships between variables because the data used in 1994 were cross-sectional. In future studies, social economic status such as house income and social support (support money from offspring, offspring visit) should be included. Third, according to advanced studies on the validity of self-reports, social desirability in the process of collecting data may be a problem $[39,40]$. The data used were subjective with regard to how elderly life satisfaction varies according to offspring gender, but over-reporting is negligible because the reliability was higher due to the skilled interviewers. Finally, the number of people 85 years of age and older was relatively low; thus, the analytical interpretations were insufficient. Future studies should address these limitations.

\section{References}

[1]. National Statistics White Paper(2011) National Center for Statistics 2012

[2]. Adams DL. Analysis of a life satisfaction index. J Gerontol 1969;24:470-4.

[3]. Krause N. Perceived health problems, formal/informal support, and life sat- 
isfaction among older adults. J Gerontol 1990;45:S193-205.

[4]. Lohr MJ, Essex MJ, Klein MH. The relationships of coping responses to physical health status and life satisfaction among older women. J Gerontol 1988;43:P54-60.

[5]. Osberg JS, McGinnis GE, DeJong G, et al. Life satisfaction and quality of life among disabled elderly adults. J Gerontol 1987;42:228-30.

[6]. Soumerai SB, Avorn J. Perceived health, life satisfaction, and activity in urban elderly: a controlled study of the impact of part-time work. J Gerontol 1983;38:356-62.

[7]. Spreitzer E, Snyder EE. Correlates of life satisfaction among the aged. J Gerontol 1974;29:454-8.

[8]. Usui WM, Keil TJ, Durig KR. Socioeconomic comparisons and life satisfaction of elderly adults. J Gerontol 1985;40:110-4.

[9]. Jung M, Muntaner C, Choi M. Factors related to perceived life satisfaction among the elderly in South Korea. J Prev Med Public Health 2010;43:292300 .

[10]. Collette J. Sex differences in life satisfaction: Australian data. J Gerontol 1984;39:243-5.

[11]. Liang J. Sex differences in life satisfaction among the elderly. J Gerontol 1982;37:100-8.

[12]. Kim D. The Study on the Development of the Korean Elderly's Successful Aging Scale. Korean Academy of Social Welfare 2008;60:211-31.

[13]. Choi H, Back J, Seo S. The Perception of Successful Aging among Korean Elderly. The Korean Home Management Association 2005;23:1-10.

[14]. Kim M, Shin K. The Study on the Development of the "Successful Aging" Scale for Korean Elderly. The Korean Gerontological Society 2005;25:35-52.

[15]. Arnold F. Measuring the effect of sex preference on fertility: the case of Korea. Demography 1985;22:280-8.

[16]. Park CB. Preference for sons, family size, and sex ratio: an empirical study in Korea. Demography 1983;20:333-52.

[17]. Andersson G, Hank K, Ronsen M, et al. Gendering family composition: sex preferences for children and childbearing behavior in the Nordic countries. Demography 2006;43:255-67.

[18]. Clark S. Son preference and sex composition of children: evidence from India. Demography 2000;37:95-108.

[19]. Khan MA, Sirageldin I. Son preference and the demand for additional children in Pakistan. Demography 1977;14:481-95.

[20]. Lhila A, Simon KI. Prenatal health investment decisions: does the child's sex matter? Demography 2008;45:885-905.

[21]. Rahman M, Da Vanzo J. Gender preference and birth spacing in Matlab, Bangladesh. Demography 1993;30:315-32.

[22]. Stinner WF. Sons, daughters or both?: an analysis of family sex composition preferences in the Philippines. Demography 1975;12:67-79.

[23]. Kim IS, Ohrr H, Jee SH, et al. Smoking and total mortality: Kangwha cohort study, 6-year follow-up. Yonsei Med J 1993;34:212-22.

[24]. Yun TK, Choi SY. Non-organ specific cancer prevention of ginseng: a pro- spective study in Korea. Int J Epidemiol 1998;27:359-64.

[25]. Yun TK, Choi SY, Yun HY. Epidemiological study on cancer prevention by ginseng: are all kinds of cancers preventable by ginseng? J Korean Med Sci 2001;16 Suppl:S19-27.

[26]. Hong JS, Yi SW, Kang HC, et al. Age at menopause and cause-specific mortality in South Korean women: Kangwha Cohort Study. Maturitas 2007;56:411-9.

[27]. Hong JS, Yi SW, Kang HC, et al. Body mass index and mortality in South Korean men resulting from cardiovascular disease: a Kangwha cohort study. Ann Epidemiol 2007;17:622-7.

[28]. Lee YJ, Nam CM, Kim HC, et al. [The association between obesity indices in adolescence and carotid intima-media thickness in young adults: Kangwha Study]. J Prev Med Public Health 2008;41:107-14.

[29]. Sull JW, Yi SW, Nam CM, et al. Binge Drinking and Mortality From All Causes and Cerebrovascular Diseases in Korean Men and Women: A Kangwha Cohort Study. Stroke 2009;40:2953-8.

[30]. Yi SW, Sull JW, Hong JS, et al. Association between ginseng intake and mortality: Kangwha cohort study. J Altern Complement Med 2009;15:921-8.

[31]. Sull JW, Yi SW, Nam CM, et al. Binge Drinking and Hypertension on Cardiovascular Disease Mortality in Korean Men and Women: A Kangwha Cohort Study. Stroke 2010;41:2157-62.

[32]. Yi SW, Sull JW, Linton JA, et al. Alcohol consumption and digestive cancer mortality in Koreans: the Kangwha Cohort Study. J Epidemiol 2010;20:20411 .

[33]. Neugarten BL, Havighurst RJ, Tobin SS. The measurement of life satisfaction. J Gerontol 1961;16:134-43.

[34]. Wood V, Wylie ML, Sheafor B. An analysis of a short self-report measure of life satisfaction: correlation with rater judgments. J Gerontol 1969;24:465-9.

[35]. Elliot FR. The family: change or continuity?: MacMillan education London 1986.

[36]. Chung W, Das Gupta M. Why is son preference declining in South Korea? The role of development and public policy, and the implications for china and India. The Role of Development and Public Policy, and the Implications for China and India (October 1, 2007) World Bank Policy Research Working Paper Series, Vol 2007.

[37]. Wilson DK, Kliewer W, Bayer L, et al. The influence of gender and emotional versus instrumental support on cardiovascular reactivity in AfricanAmerican adolescents. Annals of Behavioral Medicine 1999;21:235-43.

[38]. Seeman T. Support \& Social Conflict: Section One - Social Support. Psychosocial Notebook 2008;2:5-14.

[39]. Gordon NP, Hiatt RA, Lampert DI. Concordance of self-reported data and medical record audit for six cancer screening procedures. J Natl Cancer Inst 1993;85:566-70.

[40]. McPhee SJ, Nguyen TT, Shema SJ, et al. Validation of recall of breast and cervical cancer screening by women in an ethnically diverse population. Prev Med 2002;35:463-73. 